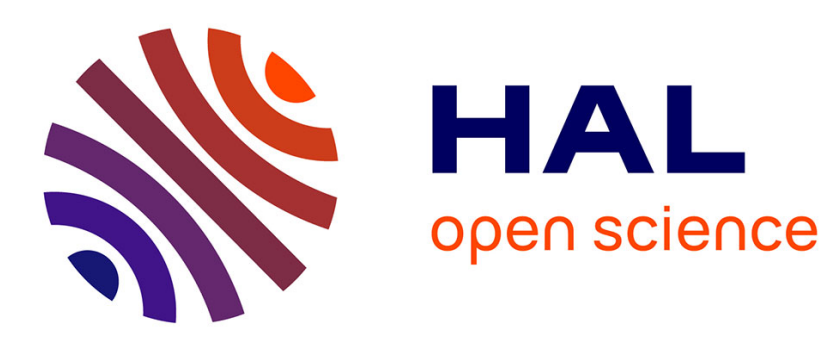

\title{
Quantification of the Adjacency Effect on Measurements in the Thermal Infrared Region
}

Xiaopo Zheng, Zhao-Liang Li, Xia Zhang, Guofei Shang

\section{To cite this version:}

Xiaopo Zheng, Zhao-Liang Li, Xia Zhang, Guofei Shang. Quantification of the Adjacency Effect on Measurements in the Thermal Infrared Region. IEEE Transactions on Geoscience and Remote Sensing, 2019, 57 (12), pp.9674-9687. 10.1109/TGRS.2019.2928525 . hal-02377704

\section{HAL Id: hal-02377704 https://hal.science/hal-02377704}

Submitted on 30 Nov 2020

HAL is a multi-disciplinary open access archive for the deposit and dissemination of scientific research documents, whether they are published or not. The documents may come from teaching and research institutions in France or abroad, or from public or private research centers.
L'archive ouverte pluridisciplinaire $\mathbf{H A L}$, est destinée au dépôt et à la diffusion de documents scientifiques de niveau recherche, publiés ou non, émanant des établissements d'enseignement et de recherche français ou étrangers, des laboratoires publics ou privés. 


\title{
Quantification of the Adjacency Effect on Measurements in the Thermal Infrared Region
}

\author{
Xiaopo Zheng, Zhao-Liang Li, Xia Zhang and Guofei Shang
}

\begin{abstract}
Sensor-observed energy from adjacent pixels, known as the adjacency effect, influences land surface reflectivity retrieval accuracy in optical remote sensing. As the spatial resolution of thermal infrared (TIR) images increases, the adjacency effect may influence land surface temperature (LST) retrieval accuracy in TIR remote sensing. However, to our knowledge, few studies have focused on quantifying this adjacency effect on TIR measurements. In this study, a forward adjacency effect radiative transfer model (FAERTM) was developed to quantify the adjacency effect on high-spatial-resolution TIR measurements. The model was verified to be in good agreement with moderate resolution atmospheric transmission (MODTRAN) code, with a discrepancy $<0.15 \mathrm{~K}$. The adjacency effect on target pixel observations was found to be negligible beyond $3 \mathrm{~km}$. Variations in aerosol type only slightly influenced adjacency effect magnitude. However, the adjacency effect quickly increased with increasing image spatial resolution, adjacent pixel temperature, and aerosol density. According to simulation results, the adjacency effect can be $>3 \mathrm{~K}$ in some cases. These findings indicate that the adjacency effect should be considered when retrieving LSTs from TIR measurements, at least in some specific conditions. The proposed FAERTM provides a useful model for quantifying and addressing the adjacency effect on TIR measurements.
\end{abstract}

Index Terms-Adjacency effect, high-spatial-resolution, radiative transfer model, thermal infrared.

\section{INTRODUCTION}

$\mathrm{L}$ AND surface temperature (LST) is an important input parameter for many domains, including evapotranspiration, vegetation monitoring, and global climate change [1-5]. Remote sensing provides an efficient method for obtaining regional and global LST images. LSTs are generally retrieved using microwave (MW) and thermal infrared (TIR) spectral measurements. However, even though MWs can penetrate through clouds, MW measurements have low spatial resolution [6]. Furthermore, these yield the "sub-surface temperature" instead of the "skin temperature" provided by TIR remote sensing, and MW measurements are also sensitive to soil moisture and surface roughness $[7,8]$. TIR observations are consequently more suitable for obtaining LSTs. A wide variety of LST retrieval algorithms have been developed over several

This work has been funded by the China Scholarship Council (CSC).

X. Zheng is with ICube, UdS, CNRS, 67412 Illkirch, France (e-mail: xiaopocpu@gmail.com)

Z.-L. Li is with ICube, UdS, CNRS, 67412 Illkirch, France, and also with Key Laboratory of Agricultural Remote Sensing, Ministry of Agriculture/Institute of Agricultural Resources and Regional Planning, Chinese decades [5, 9]; these can be roughly classified into four categories: single-channel methods [10-12], multi-channel methods (such as the split window (SW) method [13-18] and temperature emissivity separation (TES) method [19]), dualangle methods [20], and day/night methods [21, 22]. All of these methods have been designed to remove atmospheric and land surface emissivity (LSE) effects and perform well for current TIR images [23-26]. However, to our knowledge, the adjacency effect has not been considered during the derivation of these LST retrieval methods. Because the adjacency effect is either assumed to be already addressed in the pre-processing steps or is considered to be negligible.

The adjacency effect is defined as sensor-observed energy reflected or emitted from adjacent pixels [27, 28]. Its influence has already been well addressed in the visible and near-infrared (VIS-NIR) spectral region [29-32]. Existing methods for addressing the adjacency effect in this region are based either on empirical relations to avoid time-consuming operations, which is practical for operational purposes [32-37], or on the atmospheric point spread function (PSF), which has a specific physical meaning but requires detailed atmospheric parameters [30, 38-43]. The strength of the adjacency effect has been shown to generally decrease with increasing wavelength $[30,39]$ because the scattering intensity of atmospheric particles is inversely dependent on wavelength [30, 39, 44-46]. Besides, according to previous studies [31, 47, 48], the adjacency effect is usually not significant in low-spatial-resolution images. Therefore, the adjacency effect has generally been neglected with current TIR images, since they have long observation wavelengths and coarse spatial resolutions. However, with continued development of remote sensing technology, highspatial-resolution TIR images can now be acquired, and there is therefore a need to quantitatively discuss the magnitude of the adjacency effect on such high-spatial-resolution TIR images.

The objective of this study is to develop a forward adjacency effect radiative transfer model (FAERTM) in order to quantify the adjacency effect for different atmospheric and imaging conditions, especially for high-spatial-resolution TIR measurements.

This paper is organized as follows. Section II describes the development of the forward adjacency effect radiative transfer

Academy of Agricultural Sciences, 100081 Beijing, China (e-mail: lizl@unistra.fr; lizhaoliang@caas.cn).

X. Zhang, G. Shang are with College of Land Resources and Urban and Rural Planning, Hebei GEO University, 050031 Shijiazhuang, China (e-mail: zhangx396@nenu.edu.cn; shangguofei@hgu.edu.cn). 
model. Section III describes the input parameters for experiments. Section IV compares the proposed model with moderate resolution atmospheric transmission (MODTRAN) code. Section V analyzes the adjacency effect for different atmospheric and imaging conditions. Finally, section VI summarizes the main findings.

\section{DEVELOPMENT OF THE FORWARD ADJACENCY EFFECT RADIATIVE TRANSFER MODEL}

In MODTRAN, the adjacency effect can only be simulated if image spatial resolution is ignored. To quantitatively study the adjacency effect for various atmospheres and image spatial resolutions, the FAERTM is therefore developed.

\section{A. Radiative Transfer Equation of FAERTM}

For simplification purposes, the following three assumptions were adopted. First, the land surface is flat, without rugged terrain and buildings. Second, observations are acquired vertically, which is usually true for high-spatial-resolution images. Third, the proportion of energy that has been scattered more than twice is insignificant. With these assumptions, adjacent pixels can only affect observed target radiance through atmospheric scattering. Bearing in mind that the energy source in the TIR region is thermal radiation (rather than sunlight), the total spectral radiance $\left(L_{\lambda}\right)$ received by the remote sensor can be divided into five components (Fig. 1). The radiative transfer equation of FAERTM can thus be expressed as follows:

$$
\begin{gathered}
L_{\lambda}=B_{\lambda}\left(T_{b \lambda}\right)=\tau_{\lambda} \varepsilon_{\lambda} B_{\lambda}\left(T_{s}\right)+\tau_{\lambda}\left(1-\varepsilon_{\lambda}\right) L_{\downarrow \lambda} \\
+L_{\uparrow \lambda}+L_{1 \lambda}+\tau_{\lambda}\left(1-\varepsilon_{\lambda}\right) \frac{L_{2 \lambda}}{1-\rho_{\lambda} S_{\lambda}}
\end{gathered}
$$

where $\lambda$ is the wavelength and $B_{\lambda}$ is the Planck function. Here, $T_{b \lambda}$ is equivalent channel brightness temperature considering the adjacency effect, $\tau_{\lambda}$ is direct atmospheric transmittance, $\varepsilon_{\lambda}$ and $T_{S}$ are LSE and LST, $L_{\downarrow \lambda}$ and $L_{\uparrow \lambda}$ are atmospheric downwelling and upwelling radiance respectively, $\rho_{\lambda}$ is land surface reflectance, and $S_{\lambda}$ is atmospheric spherical albedo at the bottom of the atmosphere. The last two items on the righthand side of (1) describe the adjacency effect: $L_{1 \lambda}$ is the single scattered adjacent pixel radiance (Fig. 1d) and $L_{2 \lambda}$ is the adjacent pixel radiance that has been reflected by the atmosphere (Fig. 1e), with $\left(1-\rho_{\lambda} S_{\lambda}\right)$ representing illumination enhancement due to the trapping mechanism. The critical problem of FAERTM is then to model $L_{1}$, and $L_{2}$ :

$$
L=B\left(T_{b}\right)=\tau \varepsilon B\left(T_{S}\right)+\tau(1-\varepsilon)\left(L_{\downarrow}+\frac{L_{2}}{1-\rho S}\right)+L_{\uparrow}+L_{1}
$$

with the subscript $\lambda$ omitted for simplicity.

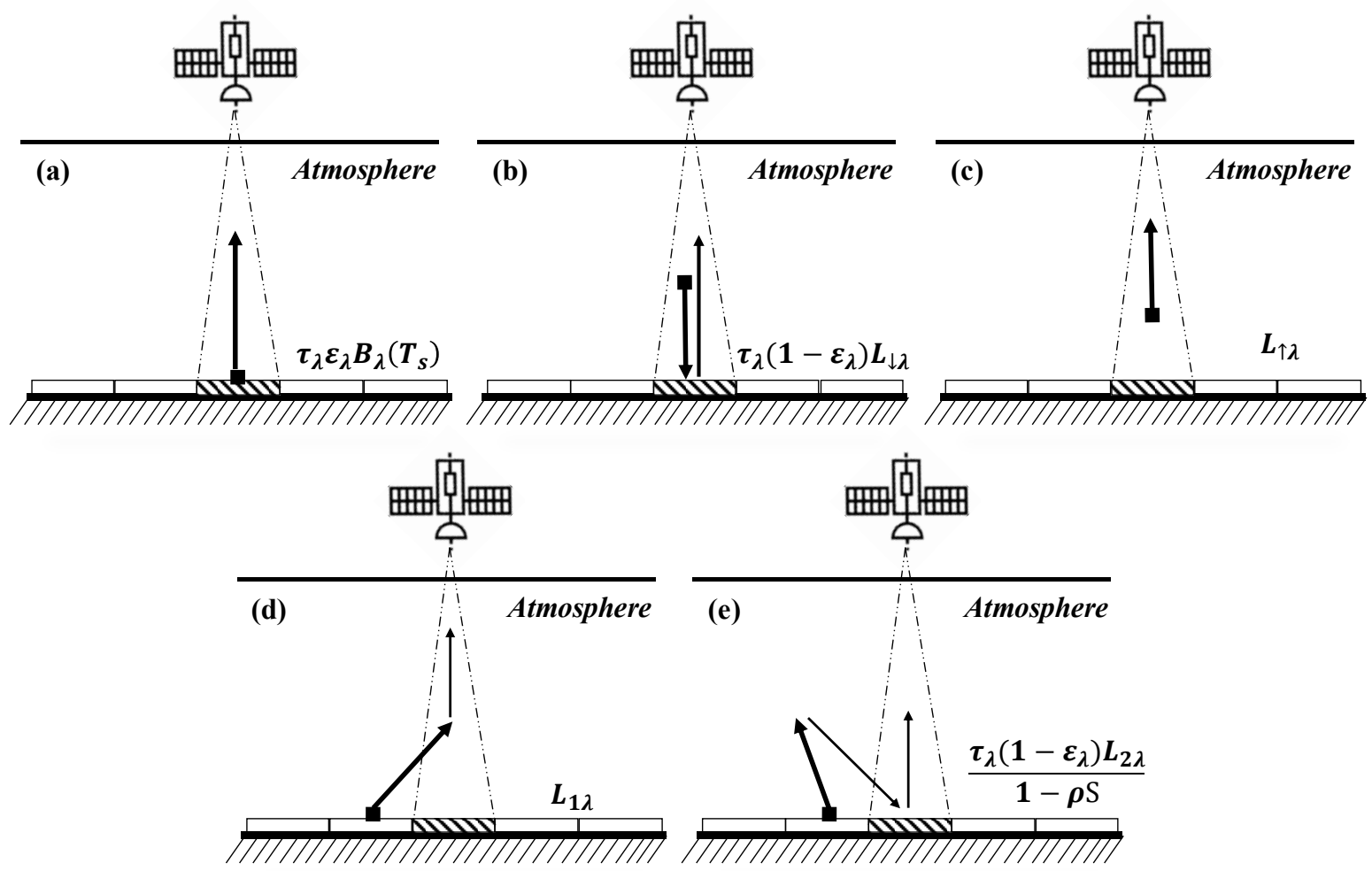

Fig. 1. Radiation sources of at-sensor observations. The surface pitches with and without shading represent target and adjacent pixels, respectively. Solid cubes indicate emission sources. The five sources include (a) target-emitted radiance; (b) target-reflected atmospheric downwelling radiance; (c) atmospheric upwelling radiance; (d) single scattered adjacent pixel radiance; and (e) adjacent pixel radiance that has been reflected by the atmosphere and then reflected by the target pixel. 


\section{B. Single Scattered Adjacent Pixel Radiance $\left(L_{1}\right)$}

We assume an adjacent pixel $A_{i, j}$ with LST and LSE of $T_{i, j}$ and $\varepsilon_{i, j}$, respectively (Fig. 2). The emitted radiance of this adjacent pixel $\left(R_{i, j}\right)$ can be given by:

$$
R_{i, j}=\varepsilon_{i, j} B\left(T_{i, j}\right)+\left(1-\varepsilon_{i, j}\right) L_{\downarrow}
$$

where $L_{\downarrow}$ is atmospheric downwelling radiance. Based on the radiative transfer theory, the radiance $\left(R 1_{i, j}\right)$ that arrives at an infinite thin atmosphere $\left(C_{h}\right)$ at height $h$ in the instantaneous field-of-view (IFOV) can be expressed by:

$$
R 1_{i, j}=R_{i, j} e^{-t\left(\mid \overrightarrow{A_{i, j} C_{h}}\right)}
$$

where $t\left(\left|\overrightarrow{A_{l, j} C_{h}}\right|\right)$ is the optical depth of the atmosphere between $A_{i, \mathrm{j}}$ and $C_{h}$.

Let $d t_{h}^{s c a}$ be the atmospheric scattering optical depth of the infinite thin atmosphere $C_{h}$. The scattered radiance $\left(R 1_{i, j}^{s c a}\right)$ when light passes through $d t_{h}^{s c a}$ is given by:

$$
R 1_{i, j}^{s c a}=R 1_{i, j} d t_{h}^{s c a}
$$

The fraction $(\psi 1)$ of scattered energy that is scattered into the sensor direction can be calculated by introducing the scattering phase function $(P)$, which is related to the wavelength and scattering angle. Assuming that the area of $A_{i, j}$ and the sensor are both small, according to the reciprocity theorem, the fraction of scattered energy is the same when source and receiver are exchanged [49]. If the sensor is considered as the radiation source, $\psi 1$ therefore equals the fraction of scattered energy that is scattered into $A_{i, j}$ [50]:

$$
\psi 1=P(\lambda, \theta) \Omega_{A_{i, j} \rightarrow C_{h}} .
$$

Here, $\theta=\arccos \left(\frac{\overrightarrow{C_{h} A_{l, j}} \cdot \overrightarrow{C_{h} T}}{\left|\overrightarrow{C_{h} A_{l, l} \mid}\right|\left|\overrightarrow{C_{h} T}\right|}\right)$ is the angle between the vector $\overrightarrow{C_{h} A_{l, j}}$ and $\overrightarrow{C_{h} T}$ in Fig. 2 . The letter $T$ represents the position of the target pixel and $\Omega_{A_{i, j} \rightarrow C_{h}}$ is the solid angle that the adjacent pixel $A_{i, \mathrm{j}}$ expands to the scattering point $C_{h}$. Both $\Omega_{A_{i, \mathrm{j}} \rightarrow C_{h}}$ and $\theta$ are related to imaging spatial resolution.

If the size of $A_{i, j}$ fails to meet the small area assumption of the reciprocity theorem, it can be divided into several small pitches; $\psi 1$ of each pitch can then be calculated. The sum of the fractions for each small pitch describes $\psi 1$ for $A_{i, \mathrm{j}}$.

Assuming the atmospheric optical depth between $C_{h}$ and sensor $O$ is $t\left(\left|\overrightarrow{C_{h} O}\right|\right)$, the proportion of $A_{i, j}$ emitted radiance $\left(R 1_{i, j}^{\text {sensor }}\right)$ that can be observed by the sensor is given by:

$$
R 1_{i, j}^{\text {sensor }}=R 1_{i, j}^{\text {sca }} \psi 1 e^{-t\left(\left|\overrightarrow{C_{h} O}\right|\right)} .
$$

Substituting (4) (6) into (7), we get:

$$
R 1_{i, j}^{\text {sensor }}=R_{i, j} e^{-t\left(\left|\overrightarrow{\mid i_{i, j} C_{h}}\right|\right)} e^{-t\left(\left|\overrightarrow{C_{h} O}\right|\right)} P(\lambda, \theta) \Omega_{A_{i, j} \rightarrow C_{h}} d t_{h}^{s c a}
$$

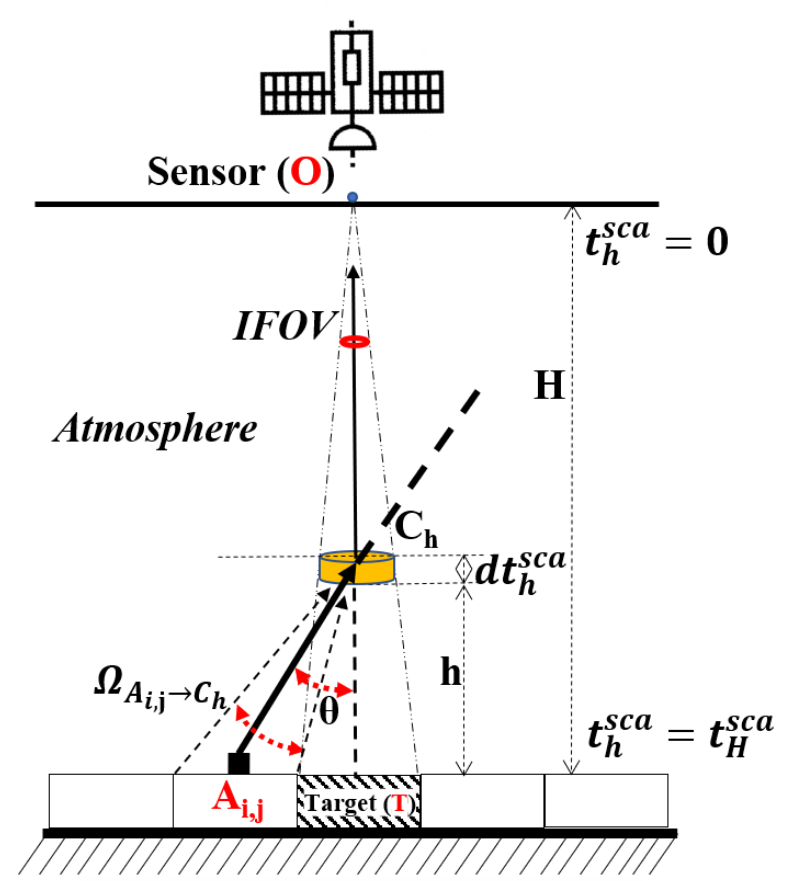

Fig. 2. Illustration of single scattered adjacent pixel radiance $\left(L_{1}\right)$.

When integrating $R 1_{i, j}^{\text {sensor }}$ vertically through the whole IFOV, the contribution of $A_{i, \mathrm{j}}$ to the final observed radiance $\left(L_{i, j}^{1}\right)$ can be expressed by:

$$
L_{i, j}^{1}=\int_{t_{H}^{s c a}}^{0} R_{i, j} e^{-t\left(\left|\overrightarrow{A_{i, j} C_{h}}\right|\right)} e^{-t\left(\left|\overrightarrow{C_{h} O}\right|\right)} P(\lambda, \theta) \Omega_{A_{i, j} \rightarrow C_{h}} d t_{h}^{s c a}
$$

After integrating $L_{i, j}^{1}$ over all adjacent pixels, the single scattered adjacent pixel radiance $\left(L_{1}\right)$ can be given by:

$$
L_{1}=\int_{-\infty}^{+\infty} \int_{-\infty}^{+\infty} L_{i, j}^{1} d i d j
$$

where subscripts $i, j$ represent the position of the adjacent pixels.

\section{Target-Reflected Adjacent Pixel Radiance (RAD)}

While the target pixel reflects atmospheric downwelling irradiance upward, the atmosphere can also reflect ground upwelling radiance downward, i.e., back to the ground. This atmosphere-reflected downward radiance can be reflected by the target pixel into the sensor, contributing to the adjacency effect.

Assuming that land surface temperature and emissivity for 
background pixels are $T_{b c k}$ and $\varepsilon_{b c k}$ respectively, the radiance $\left(L_{2}\right)$ emitted from the ground and reflected by the atmosphere can be given by:

$$
L_{2}=\varepsilon_{b c k} B\left(T_{b c k}\right) S
$$

where $\mathrm{S}$ is the atmospheric spherical albedo at the bottom of the atmosphere. Considering the trapping mechanism between land surface and atmosphere, an illumination enhancement factor, which is actually the sum of a geometric sequence, is introduced to compensate for atmosphere-reflected ground radiance:

$$
\frac{L_{2}}{1-\rho \mathrm{S}}=\frac{\varepsilon_{b c k} B\left(T_{b c k}\right) S}{1-\rho \mathrm{S}}
$$

here, $\rho=1-\varepsilon_{b c k}$, representing land surface reflectance.

If the land surface is heterogeneous, $T_{b c k}$ and $\varepsilon_{b c k}$ should refer to averaged land surface temperature and emissivity, which can be estimated by introducing the PSF as the ground weighting function. Assuming $\mathrm{g}_{i, j}$ is the PSF, or the ground weighting function for a given atmosphere, then $T_{b c k}$ and $\varepsilon_{b c k}$ can be given by:

$$
\begin{gathered}
\varepsilon_{\mathrm{bck}}=\int_{-\infty-\infty}^{+\infty} \int_{i, j}^{+\infty} g_{i, j} d i d j \\
T_{b c k}=B^{-1}\left(\frac{\int_{-\infty-\infty}^{+\infty} \int_{i, j}^{+\infty} B\left(T_{i, j}\right) g_{i, j} d i d j}{\varepsilon_{b c k}}\right)
\end{gathered}
$$

where subscripts $i, j$ represent the position of the land surface pixels. $B^{-1}$ is the inverse of the Planck function.

In order to obtain $g_{i, j}$, (9) in Section II.B was reconsidered. From (9), it can be easily shown that the unnormalized value of $\mathrm{g}_{i, j}\left(\mathrm{~g}_{i, j}^{\text {unnormal }}\right)$ is defined as:

$$
\mathrm{g}_{i, j}^{\text {unnormal }}=\int_{t_{H}^{s c a}}^{0} e^{-t\left(\left|\overrightarrow{A_{i, j} C_{h}}\right|\right)} e^{-t\left(\left|\overrightarrow{C_{h} O}\right|\right)} P(\lambda, \theta) \Omega_{A_{i, j} \rightarrow C_{h}} d t_{h}^{s c a}
$$

After normalization of $\mathrm{g}_{i, j}^{\text {unnormal }}, \mathrm{g}_{i, j}$ can be given by:

$$
g_{i, j}=\frac{\mathrm{g}_{i, j}^{\text {unnormal }}}{\int_{-\infty-\infty}^{+\infty+\infty} \int_{-\infty}^{\text {unnormal }} d i d j}
$$

Finally, by combining (12) (16), the target-reflected adjacent pixel radiance (RAD) can be acquired by:

$$
R A D=\tau(1-\varepsilon) \frac{L_{2}}{1-\rho S}=\tau(1-\varepsilon) \frac{\varepsilon_{b c k} B\left(T_{b c k}\right) S}{1-\left(1-\varepsilon_{b c k}\right) S}
$$

where $\tau$ is direct atmosphere transmittance and $\varepsilon$ is target pixel emissivity. When the land surface is homogenous, $\varepsilon_{b c k}$ should be the same as $\varepsilon$.

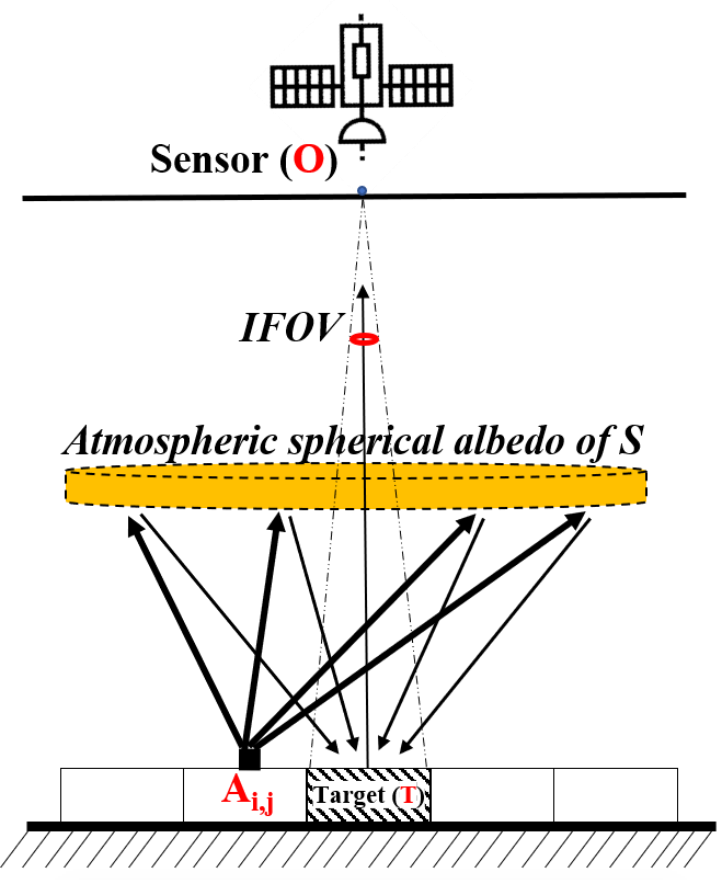

Fig. 3. Illustration of target-reflected adjacent pixel radiance.

\section{Radiance Contributed by Target Pixel and Atmosphere}

The first three terms on the right-hand side of (2) (Fig. 1(a)(c)) can be calculated after acquiring $\tau, L_{\downarrow}$, and $L_{\uparrow}$. In this study, MODTRAN was used to calculate these parameters for different atmospheric conditions. Since the single scattered adjacent pixel radiance $\left(L_{1}\right)$ and the target-reflected adjacent pixel radiance $(R A D)$ were considered separately in FAERTM (see (2)), the $L_{\downarrow}$ and $L_{\uparrow}$ should be the intrinsic atmospheric radiance. However, the MODTRAN output path thermal radiance (related to $L_{\uparrow}$ ) and ground reflected radiance (related to $L_{\downarrow}$ ) would contain the contribution of land surface radiation if the land surface temperature was left as default in MODTRAN. Therefore, in order to exclude the influence of land surface radiation on intrinsic atmospheric quantities, in this study, $L_{\uparrow}$ and $L_{\downarrow}$ were calculated using MODTRAN by setting

$$
=1.0, \mathrm{Ts}=0.00001 \mathrm{~K} \text { and }=0.0, \mathrm{Ts}=0.00001 \mathrm{~K} \text {, }
$$
respectively.

\section{E. Quantification of Adjacency effect on satellite TIR measurements}

If the adjacency effect terms $\left[L_{1}, \tau(1-\varepsilon) \frac{L_{2}}{1-\rho S}\right]$ are omitted from (2), FAERTM can be reduced to the traditional thermal infrared radiative transfer equation $[13,16,21]$ : 


$$
L=B\left(T_{b}^{0}\right)=\tau \varepsilon B\left(T_{s}\right)+\tau(1-\varepsilon) L_{\downarrow}+L_{\uparrow}
$$

where $T_{b}^{0}$ is the equivalent channel brightness temperature of the satellite TIR measurement, without considering adjacency effect. In fact, (18) is the basic function, based on which commonly-used LST retrieval algorithms were developed. However, because the temperature and emissivity of adjacent pixels are always not equal to zero, the scattered adjacent pixels' radiation will also contribute to observed target pixel radiance. When using existing LST retrieval algorithms, target pixel temperature retrieval accuracy can therefore be affected, even if adjacent pixels have the same temperature and emissivity as the target pixel. The adjacency effect (here defined as observed target radiation difference between a case with adjacent pixels' radiation and one without) therefore merits further research. In order to intuitively represent the adjacency effect, the difference $\left(\Delta T_{b}\right)$ between $T_{b}$ and $T_{b}^{0}$ will be used in the following sections:

$$
\Delta T_{b}=T_{b}-T_{b}^{0}
$$

Additionally, land surface has always been assumed to be homogenous in practical applications. In these cases, satellite observed radiance can be given by:

$$
L=B\left(T_{b}^{1}\right)=\tau \varepsilon B\left(T_{S}\right)+\tau(1-\varepsilon)\left(L_{\downarrow}+\frac{L_{2}^{h o m}}{1-\rho S}\right)+L_{\uparrow}+L_{1}^{h o m}
$$

where $L_{1}^{\text {hom }}$ and $L_{2}^{\text {hom }}$ have the same meanings as in (2) but are calculated under the assumption that adjacent pixels have the same temperature and emissivity as the target pixel. The adjacency effect, now defined as observed target radiation difference between a case with target-to-background-radiationcontrast and one without, should thus be explored. Therefore, the difference $\left(\delta T_{b}\right)$ between $T_{b}$ and $T_{b}^{1}$ was also investigated in this study:

$$
\delta T_{b}=T_{b}-T_{b}^{1}
$$

\section{SimUlation DeSCRIPTION}

\section{A. Scenario Input Simulation Parameters}

As shown in Section II, in addition to direct atmospheric transmittance, atmospheric downwelling, and upwelling radiance, which can be obtained from MODTRAN [50], FAERTM also requires the temperature and emissivity of the target and adjacent pixels, scattering phase function, scattering optical depth, and atmospheric spherical albedo at the bottom of the atmosphere to calculate the adjacency effect. Different simulation input combinations were selected to provide a variety of atmospheric and imaging scenarios. According to previous studies, in the TIR region, scattering is mainly caused by aerosol particles for flat surfaces, and the adjacency effect in TIR spectral region therefore depends mainly on aerosol [39,
46, 51]. In this study, two typical aerosol types and four visibilities were used as simulation inputs. The required direct atmospheric transmittance and atmospheric downwelling and upwelling radiance were calculated using the 1976 U.S. Standard atmosphere profiles as an example, because the adjacency effect performs similarly for other atmospheric types provided input aerosol parameters remain unchanged. In terms of imaging conditions, the adjacency effect was studied with varying wavelengths, image spatial resolutions, and temperatures and emissivities of target and adjacent pixels. Five pre-set ranges were given to study the spatial extent of the adjacency effect. Moreover, the remote sensor was placed on a satellite platform at an altitude of $705 \mathrm{~km}$. The detailed input simulation parameters are listed in Table I.

TABLE I

SCENARIO INPUT SIMULATION PARAMETERS

\begin{tabular}{ll}
\multicolumn{1}{c}{ SCENARIO INPUT SIMULATION PARAMETERS } \\
\hline \multicolumn{1}{c}{ Atmospheric conditions } \\
\hline Atmosphere model \\
Aerosol model \\
Atmospheric visibility \\
\multicolumn{1}{c}{ Imaging conditions } \\
\hline \hline Wavelength & $5,10,23,40 \mathrm{~km}$ \\
Image spatial resolution & $8,9,10,11,12 \mu \mathrm{m}$ \\
& $0.005,0.01,0.03,0.06,0.1$, \\
Temperature of target pixel (TAT_LST) & $0.25,0.5,1.0 \mathrm{~km}$ \\
Temperature of adjacent pixels & $270,290,310 \mathrm{~K}$ \\
& From TAT_LST $-30 \mathrm{~K}$ to \\
& TAT_LST $+30 \mathrm{~K}$ with a \\
Emissivity of target pixel & step of $10 \mathrm{~K}$ \\
Emissivity of adjacent pixels & $0.90,0.98$ \\
Calculation range of adjacency effect & $0.90,0.98$ \\
Sensor altitude & $1.0,2.0,3.0,4.0,5.0 \mathrm{~km}$ \\
\hline \hline
\end{tabular}

\section{B. Scattering Phase Function of FAERTM}

Another important input of FAERTM is the aerosol scattering phase function (ASPF), which determines the radiation intensity of a certain direction after scattering [47, 52]. The scattering property of normal aerosol particles was measured in a laboratory in 1983, at wavelengths ranging from 0.2 to $40 \mu \mathrm{m}$ [53]. Then, an ASPF database was built based on the Mie scattering theory and embedded in MODTRAN [50]. The database was reported to approximate exact phase functions within about $20 \%$ [50]. In this study, we used this ASPF database to calculate the adjacency effect. As shown in Fig. 4, most scattered energy is concentrated in the forward direction within a scattering angle $<60^{\circ}$, which means that distant adjacent pixels would make an insignificant contribution to the final adjacency effect. 

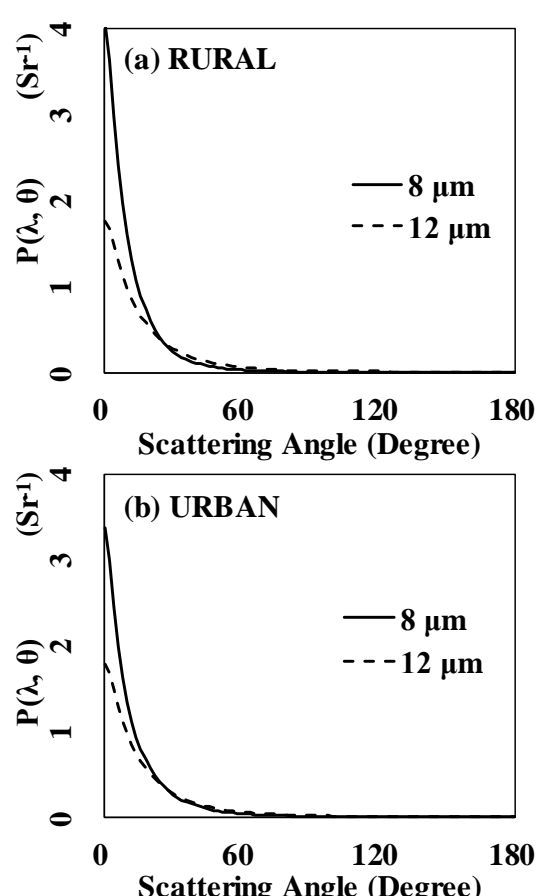

Fig. 4. Aerosol scattering phase function used in this study. Wavelengths of 8 and $12 \mu \mathrm{m}$ were used as examples for two aerosol types: (a) RURAL and (b) URBAN.

\section{Actual Satellite Data}

In order to preliminarily investigate the adjacency effect in real satellite data, MODIS (Moderate Resolution Imaging Spectroradiometer) Land Surface Temperature and Emissivity (MOD11) [54] data, with pixel size of $1000 \mathrm{~m} * 1000 \mathrm{~m}$, were introduced to represent low spatial resolution data. ASTER (Advanced Spaceborne Thermal Emission and Reflectance Radiometer) Surface Kinetic Temperature (AST08) [55] and Surface Emissivity (AST05) [56] data, with pixel size of $90 \mathrm{~m}$ * $90 \mathrm{~m}$, were used to represent high spatial resolution data. The study area was Zhangye, China (100²6'59" E, 38 55'33" N), where the main surface coverage types are the Gobi Desert and oases. The data used in this study were acquired on April 24, 2013 onboard the same platform TERRA (Fig. 5).

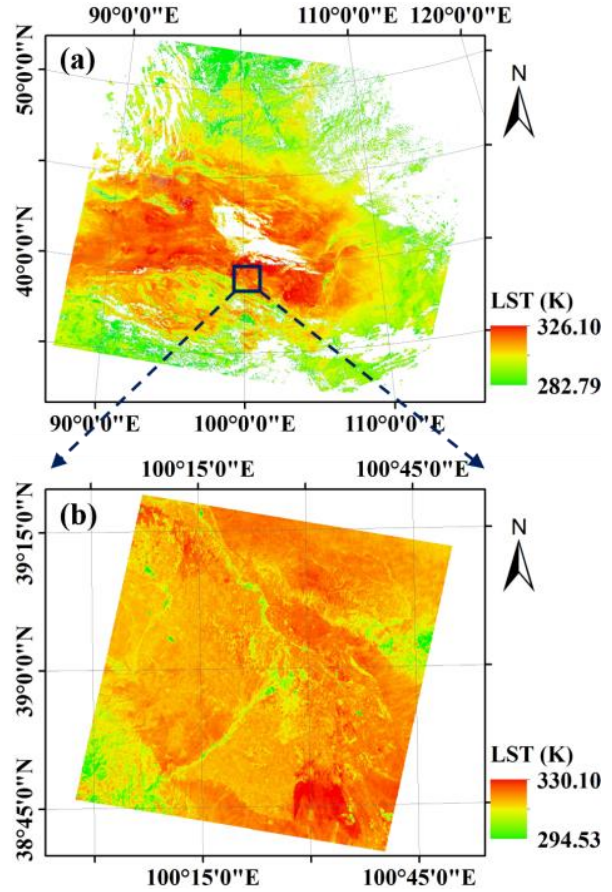

Fig. 5. LST images of the study area obtained from (a) MOD11 product of MODIS observations, and (b) AST08 product of ASTER observations.

\section{COMPARISON BETWEEN FAERTM AND MODTRAN}

In MODTRAN, the adjacency effect is modeled by setting the target pixel in a uniform background [57]. The background is defined based on two parameters: "area-averaged" temperature and "area-averaged" emissivity [50, 58]. These parameters are usually obtained by convoluting background LST and LSE with the atmospheric PSF. In this section, target and adjacent pixels were first assumed to be homogeneous. Our results are thus comparable with those from MODTRAN, without requiring calculation of the atmospheric PSF. Second, a scenario with two different surfaces was assumed, as can usually be found at the seashore. In this case, the land surface is heterogenous and the PSF is therefore needed, which can be estimated from (15) and (16).

\section{A. For Homogeneous Land Surfaces}

In this case, adjacent pixels have the same LST and LSE as the target pixel. LSE was fixed at 0.9 while two LSTs (270 K, $310 \mathrm{~K}$ ) were considered. The aerosol type was set as RURAL. Differences in simulated satellite brightness temperature between MODTRAN ( $\left.T_{\text {MODTRAN }}\right)$ and FAERTM $\left(T_{\text {FAERTM }}\right)$ were calculated (Figs. 6(a) and 6(b)). In addition, considering that the target-reflected adjacent pixel radiance $(R A D)$ can be obtained in MODTRAN by comparing radiances reflected from a target pixel (LST=270 K, LST=310 K) and a non-emitted background $\left(T_{b c k}=0 \mathrm{~K}\right)$ with those from a homogeneous surface $\left(T_{b c k}=270 \mathrm{~K}, T_{b c k}=310 \mathrm{~K}\right)$, this portion of radiance calculated from FAERTM (RAD $\left.D_{F A E R T M}\right)$ was also separately compared with that from MODTRAN (RAD MODTRAN $)$ (Fig. 6(c)). 

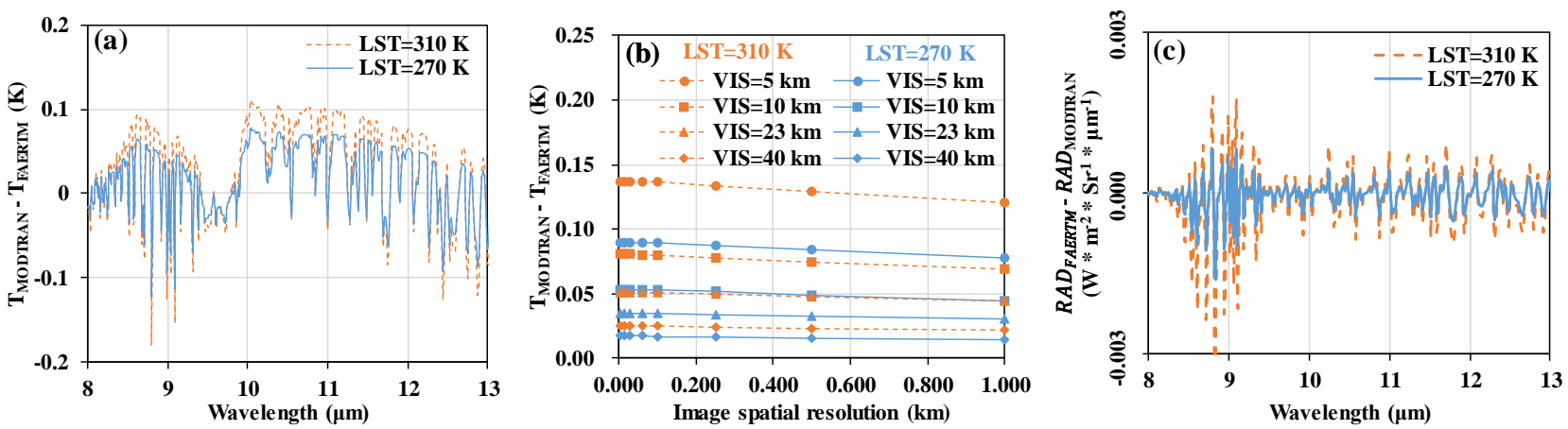

Fig. 6. Difference in satellite brightness temperature and target-reflected adjacent pixel radiance between MODTRAN and FAERTM simulations. LSE and aerosol type were fixed as 0.9 and RURAL, respectively. (a) Simulated satellite brightness temperature difference as a function of wavelength, with atmospheric visibility of $10 \mathrm{~km}$ and image spatial resolution of $0.03 \mathrm{~km}$. (b) Simulated satellite brightness temperature difference for different atmospheric visibilities (VIS) and image spatial resolutions, with wavelength of $10 \mu \mathrm{m}$. (c) Difference in simulated target-reflected adjacent pixel radiance as a function of wavelength, with atmospheric visibility of $10 \mathrm{~km}$.

As shown in Figs. 6(a) and 6(b), compared with MODTRAN, the proposed model slightly underestimated the adjacency effect for most of the spectral region. Since the difference in target-reflected adjacent pixel radiance between MODTRAN and FAERTM is small (Fig. 6(c)), the underestimation is likely caused by the neglect of multiple scattering in the $L_{1}$ calculation in this study; conversely, this is calculated in MODTRAN [50, 59-61]. Because more multiple scattering occurs in a turbid atmosphere than in a clear atmosphere, the difference between the proposed model and MODTRAN also increased as atmospheric visibility decreased (Fig. 6(b)). In addition, it is noticed that the discrepancies between the two models seem to follow the shape of the atmospheric transmissivity spectrum (Fig. 6(a)). The possible reason may be that the adjacency effect is in fact suppressed by atmospheric transmittance in both FAERTM and MODTRAN when considering satellite observations, because atmospheric optical depth was used to model the adjacency effect, as discussed in Sections II.B and II.C. Therefore, smaller atmospheric transmittance would decrease the adjacency effect in both models, leading to a relatively smaller discrepancy between the two models in contrast to cases with larger atmospheric transmittances, and then making the discrepancies follows the shape of the atmospheric transmissivity spectrum along wavelength. But overall, even in extreme conditions, with atmospheric visibility of $5 \mathrm{~km}$, LST of $310 \mathrm{~K}$, and wavelength of $10 \mu \mathrm{m}$, the difference was no larger than $0.15 \mathrm{~K}$ with respect to an adjacency effect of $2.3 \mathrm{~K}$ calculated by MODTRAN. Therefore, the proposed model is accurate for capturing signal variation caused by the adjacency effect.

\section{B. For Heterogeneous Land Surfaces}

In this case, a scenario with two different surfaces was considered, with the left part having emissivity of 0.9 and the right part having emissivity of 0.98 (Fig. 7). The temperature of the right part was fixed at $290 \mathrm{~K}$ while the temperature of the left part varied from $270 \mathrm{~K}$ to $310 \mathrm{~K}$, with a step of $20 \mathrm{~K}$. The target is located on the left border of the right part, with a pixel size of $0.03 * 0.03 \mathrm{~km}$. Atmospheric visibility was set at $10 \mathrm{~km}$ and aerosol type was set as RURAL. The PSF required in this case was estimated from (15) and (16) given in Section II.C. By inputting the scenario parameters, the difference in simulated satellite brightness temperature between MODTRAN $\left(T_{\text {MODTRAN }}\right)$ and FAERTM $\left(T_{\text {FAERTM }}\right)$ was calculated. The results at $10.0 \mu \mathrm{m}$ were given as an example (Fig. 8).

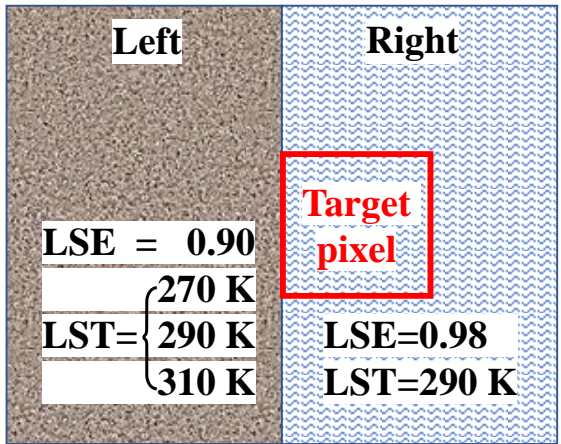

Fig. 7. Assumed scenario with two different surfaces. The target has the pixel size of $0.03 * 0.03 \mathrm{~km}$.

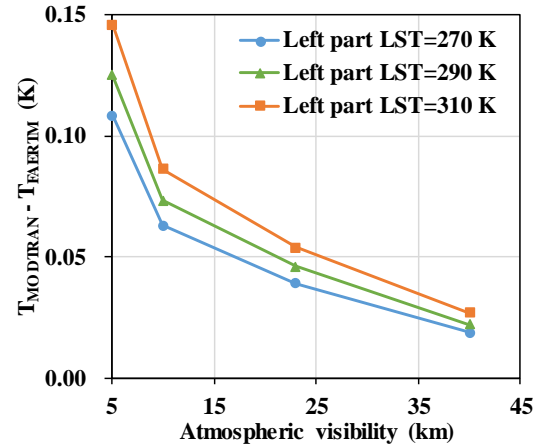

Fig. 8. Difference in simulated satellite brightness temperature between MODTRAN and FAERTM at $10 \mu \mathrm{m}$ for the assumed scenario. The left part has emissivity of 0.9 and the right part has emissivity of 0.98 . The temperature of the right part was fixed at $290 \mathrm{~K}$ while the temperature of the left part varied from $270 \mathrm{~K}$ to $310 \mathrm{~K}$, with a step of $20 \mathrm{~K}$. The aerosol type was set as RURAL.

As shown in Fig. 8, the differences in simulated satellite brightness temperature between MODTRAN and FAERTM coincide with those obtained for a homogeneous land surface. In fact, the results at wavelengths of 8.0, 9.0, 11.0 and $12.0 \mu \mathrm{m}$ were also calculated and the difference was found to be smaller than that of $10.0 \mu \mathrm{m}$. For common cases, the validation results therefore showed that the discrepancy between FAERTM and MODTRAN is usually $<0.15 \mathrm{~K}$. 


\section{RESULTS}

\section{A. Adjacency Effect Analysis on Horizontal and Vertical Calculation Range}

The integration range of the adjacency effect should be infinite horizontally and over the entire atmosphere vertically. However, aerosol density quickly decreases as altitude increases [62]. As shown in Fig. 9, aerosol scattering optical depth quickly approximates zero above $3 \mathrm{~km}$; this means that calculation of scattered radiation $>3 \mathrm{~km}$ only makes a very limited contribution to the total adjacency effect but increases calculation time. Additionally, when the adjacent pixel is far from the target pixel, the scattering angle increases, resulting in small ASPF values. Consequently, similarly to the VIS-NIR region, adjacency effect radiation is mainly related to adjacent pixels within several kilometers of the target pixel and scattered by the bottom atmospheres [28, 39]. It is therefore necessary to determine a horizontal and vertical cut-off distance for practical calculations. According to [28], the horizontal range of the adjacency effect usually has the same magnitude as the boundary aerosol scale height. For simplicity, in Fig. 10, the same value was therefore used both horizontally and vertically for each pre-set calculation range. Results showed that the adjacency effect first increased with the calculation range and then stabilized at about $3 \mathrm{~km}$. The results for other input parameters such as LST, wavelength, and image spatial resolution showed a similar pattern. The horizontal and vertical cut-off range in this study was therefore set at $3 \mathrm{~km}$.



Fig. 9. Aerosol scattering optical depth as a function of altitude for different atmospheric visibilities (VIS). The wavelength and aerosol type were set as 10 $\mu \mathrm{m}$ and RURAL, respectively. The logarithmic y-axis was used.
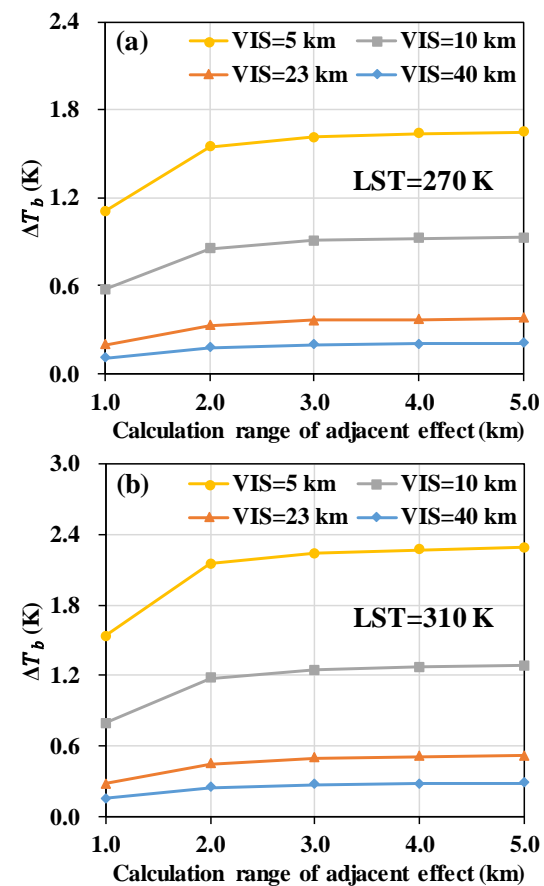

Fig. 10. Adjacency effect as a function of calculation range for different atmospheric visibilities (VIS). The wavelength, image spatial resolution, aerosol type, and LSE were set as $10 \mu \mathrm{m}, 30 \mathrm{~m}$, RURAL, and 0.90 , respectively. The target and background temperature were the same, with LSTs of (a) $270 \mathrm{~K}$ and (b) $310 \mathrm{~K}$.

\section{B. Adjacency Effect Analysis on Target and Adjacent Pixel Emissivity}

When the LSE of the target pixel decreased, the reflectance of the target pixel increased. As a result, the adjacency effect increased because more energy was reflected as the target pixel LSE changed from 0.98 to 0.90 (Fig. 11). However, the amount of increase was quite small, and different LSTs and atmospheric visibilities showed similar values. In fact, the proportion of energy scattered backward by the atmosphere in the TIR region is usually insignificant [63], indicating that the contribution of target-reflected adjacent pixel radiance is limited. Consequently, varying the target pixel LSE made no significant impact on the final sensor-observed radiance.
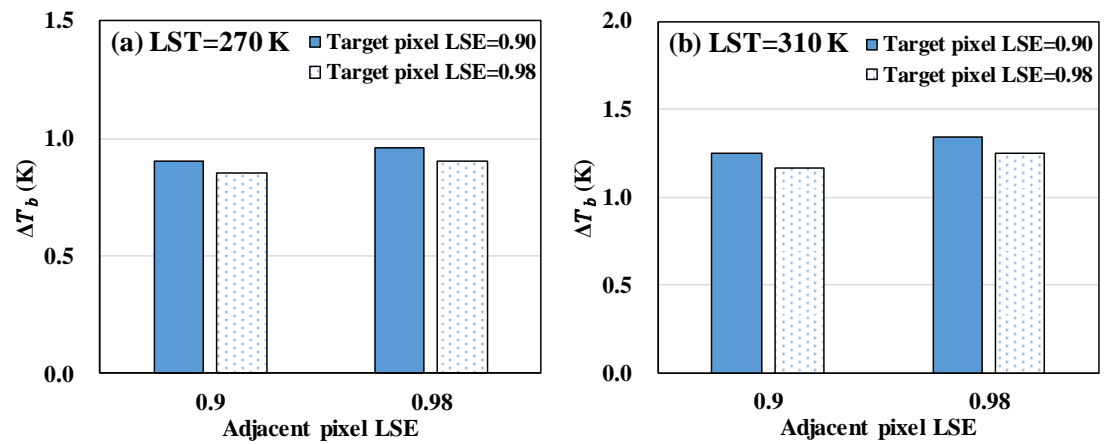

Fig. 11. Adjacency effect for different target and adjacent pixel emissivity combinations. The wavelength, image spatial resolution, aerosol type, and atmospheric visibility were $10 \mu \mathrm{m}, 30 \mathrm{~m}$, RURAL, and $10 \mathrm{~km}$, respectively. The target and background temperature were the same, with LSTs of $270 \mathrm{~K}$ or $310 \mathrm{~K}$. 


\section{Adjacency Effect Analysis on Aerosol Type and Image Spatial Resolution}

Results showed that the adjacency effect increased as image spatial resolution improved, regardless of LST (Fig. 12). For example, the adjacency effect was only about $0.3 \mathrm{~K}$ in images with a pixel size of $1.0 \times 1.0 \mathrm{~km}$. However, the adjacency effect increased by about three times as image spatial resolution increased to $5.0 \times 5.0 \mathrm{~m}$. When image spatial resolution was better than $0.03 \mathrm{~km}$, the adjacency effect was no longer dominated by image spatial resolution but was mainly controlled by other parameters, such as LST.


Fig. 12. Adjacency effect as a function of image spatial resolution for two different aerosol types. The wavelength, atmospheric visibility, and LSE were $10 \mu \mathrm{m}, 10 \mathrm{~km}$, and 0.98 , respectively. Target and background temperature were the same, with LSTs of (a) $270 \mathrm{~K}$ and (b) $310 \mathrm{~K}$.

Results also showed that the adjacency effect was more pronounced for RURAL than for URBAN aerosol types (Fig. 12). The difference varied from about $0.1 \mathrm{~K}$ to $0.2 \mathrm{~K}$ when image spatial resolution increased from $1.0 \mathrm{~km}$ to $5.0 \mathrm{~m}$. However, in other respects, the adjacency effect for these two typical aerosol types was similar. The RURAL aerosol type was therefore used in the following analysis as an example.

\section{Adjacency Effect Analysis on Atmospheric Visibility}

Atmospheric visibility describes the scattering ability of the atmosphere. The lower the atmospheric visibility, the higher the atmospheric particle density, meaning that there should be a greater adjacency effect.

As shown in Fig. 13, when atmospheric visibility decreased, the adjacency effect soon became significant, reaching up to 1.6 $\mathrm{K}$ even for a cold surface with LST of $270 \mathrm{~K}$. Additionally, the adjacency effect increased much more rapidly under conditions of large LST and high image spatial resolution. For example, in the case of an image spatial resolution of $0.03 \mathrm{~km}$ and LST of $310 \mathrm{~K}$, the adjacency effect increased from $0.27 \mathrm{~K}$ to $2.25 \mathrm{~K}$ as atmospheric visibility decreased from $40.0 \mathrm{~km}$ to $5.0 \mathrm{~km}$. In a case with image spatial resolution of $0.5 \mathrm{~km}$ and LST of $270 \mathrm{~K}$, the adjacency effect only changed from $0.13 \mathrm{~K}$ to $0.91 \mathrm{~K}$.
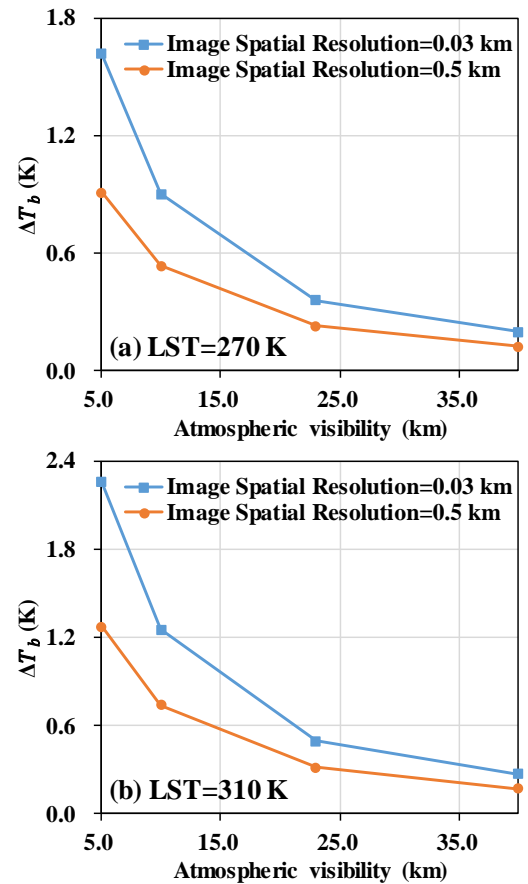

Fig. 13. Adjacency effect as a function of atmospheric visibility. The aerosol type, wavelength and LSE were RURAL, $10.0 \mu \mathrm{m}$ and 0.98 , respectively. The target and background temperature were set the same with the LST of (a) 270 $\mathrm{K}$ and (b) $310 \mathrm{~K}$.

\section{E. Adjacency Effect Analysis on Target and Adjacent Pixel Temperature}

For a specific atmospheric profile, transmitted target pixel radiance and adjacency effect radiance are the two ground energy sources that affect the final sensor-observed radiation. Fig. 14 showed that the contribution of adjacent pixels to total observed radiance increased as adjacent pixel LST increased or target pixel LST decreased. The adjacency effect on satellite measurements therefore increased with increasing adjacent pixel LST (Fig. 15). Conversely, as target pixel LST increased, the adjacency effect decreased. We take as an example a common imaging condition with atmospheric visibility of 10 $\mathrm{km}$, image spatial resolution of $30 \mathrm{~m}$, and target pixel LST of $290 \mathrm{~K}$. Increasing adjacent pixel LST from $270 \mathrm{~K}$ to $310 \mathrm{~K}$ could result in the adjacency effect increasing by about $0.8 \mathrm{~K}$ (from $0.7 \mathrm{~K}$ to $1.5 \mathrm{~K}$ ). Conversely, increasing target pixel LST from $270 \mathrm{~K}$ to $310 \mathrm{~K}$ leads to a decrease in the adjacency effect of about $0.4 \mathrm{~K}$ (from $1.3 \mathrm{~K}$ to $0.9 \mathrm{~K}$ ), with maintaining adjacent pixel LST at $290 \mathrm{~K}$.

In addition, we studied the adjacency effect, when defined as the observed target radiation difference between a case with target-to-background-radiation-contrast and one without [see (21)] (Fig. 16). Results showed that, using this definition, the adjacency effect exists only when target pixel LST is different from adjacent pixel LST. The greater the difference, the larger the adjacency effect. For instance, given a common imaging condition with atmospheric visibility of $10 \mathrm{~km}$, image spatial resolution of $30 \mathrm{~m}$, and target pixel LST of $290 \mathrm{~K}$, the adjacency 
effect increased from null to about $0.5 \mathrm{~K}$ with an increase in target-to-background-contrast from null to $30 \mathrm{~K}$. With a fixed target-to-background-contrast, the adjacency effect was a little



greater in cases where target pixel LST > adjacent pixel LST, compared to cases with target pixel LST < adjacent pixel LST.



Fig. 14. The proportion of adjacency effect radiation in total observed target radiation as a function of (a) adjacent pixel LST, and (b) target pixel LST. Aerosol type, wavelength, image spatial resolution, and LSE were RURAL, $10 \mu \mathrm{m}, 30 \mathrm{~m}$, and 0.98 , respectively.
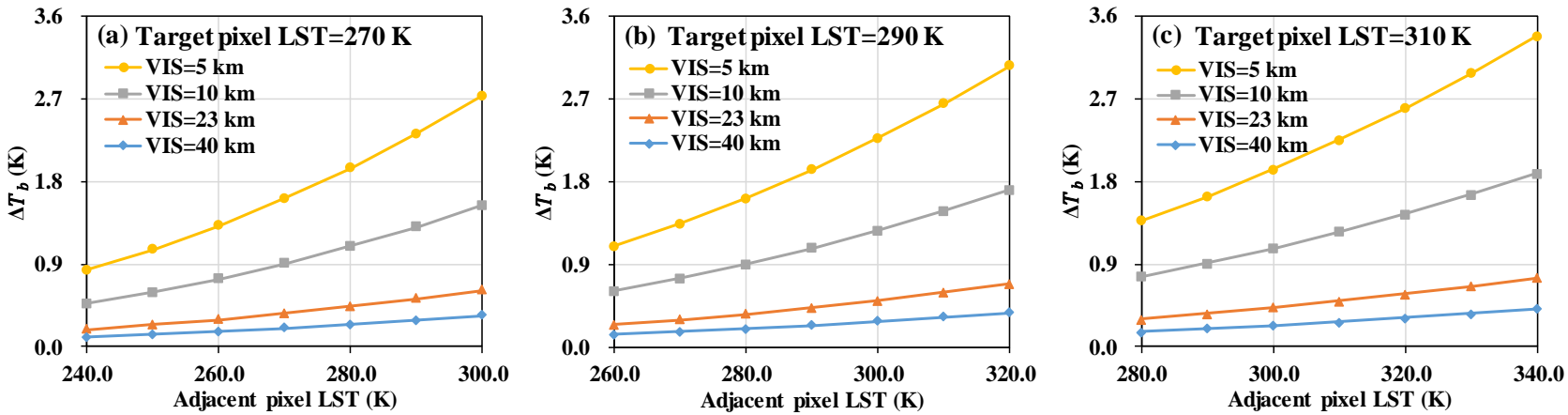

Fig. 15. Adjacency effect [defined as per (19)] as a function of adjacent pixel temperature. Aerosol type, wavelength, image spatial resolution, and LSE were RURAL, $10 \mu \mathrm{m}, 30 \mathrm{~m}$, and 0.98, respectively. Target pixel temperature (TAT_LST) was (a) $270 \mathrm{~K}$, (b) $290 \mathrm{~K}$, and (c) $310 \mathrm{~K}$. Adjacent pixel temperature varied from TAT_LST $-30 \mathrm{~K}$ to TAT_LST $+30 \mathrm{~K}$, with a step of $10 \mathrm{~K}$.
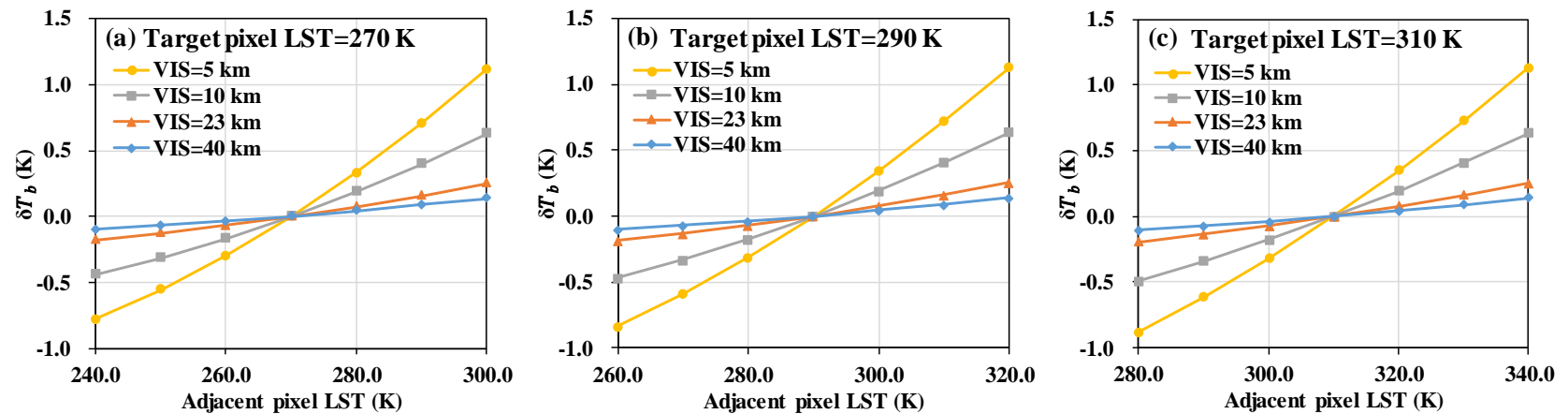

Fig. 16. Same as Fig. 15 but with adjacency effect defined by (21).

\section{F. Adjacency Effect Analysis on Wavelength}

Changing the simulated wavelength produced different adjacency effect, mainly because some parameters used in FAERTM are wavelength-dependent, such as aerosol scattering optical depth and atmospheric transmittance [see (9) and (17)]. As shown in Fig. 17, for both definitions (19) and (21), the adjacency effect decreased as wavelength increased, except for the wavelengths of 8.0 and $12.0 \mu \mathrm{m}$. The irregularity of these two positions could be explained through analysis of aerosol scattering optical depth and atmospheric transmittance of the five wavelengths.
Given the 1976 U.S Standard atmospheric type and $10 \mathrm{~km}$ atmospheric visibility, transmittances were $0.51,0.75,0.73$, 0.72 , and 0.85 for wavelengths of 8.0, 9.0, 10.0, 11.0, and 12.0 $\mu \mathrm{m}$, respectively. Aerosol scattering optical depth as a function of wavelength is given in Fig. 18. As expected, the smallest atmospheric transmittance and smallest aerosol scattering optical depth both occurred at $8 \mu \mathrm{m}$, resulting in a minimum adjacency effect at this wavelength. 

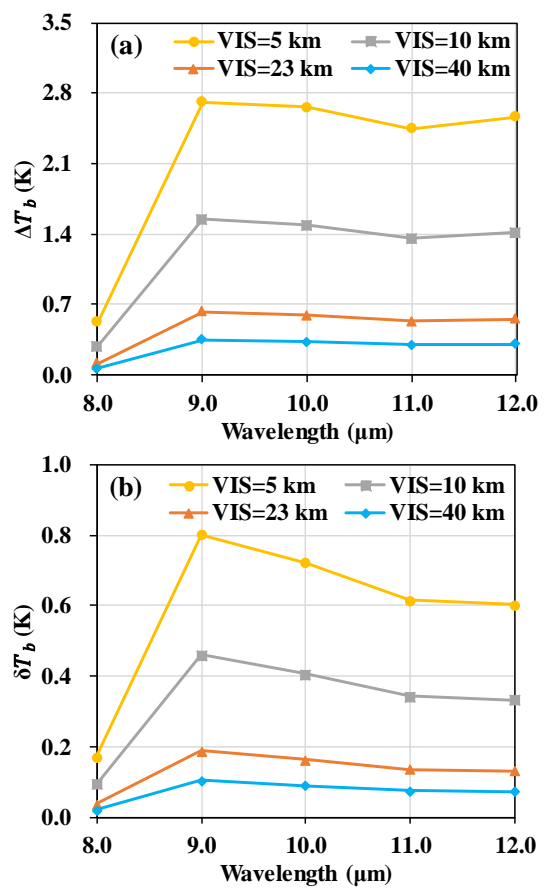

Fig. 17. Adjacency effect results, with this defined as per (a) (19), and (b) (21), as a function of wavelength for different atmospheric visibilities (VIS). Aerosol type, image spatial resolution, and LSE were RURAL, $30 \mathrm{~m}$, and 0.98 , respectively. Target and adjacent pixel temperatures were set as $290 \mathrm{~K}$ and 310 $\mathrm{K}$, respectively.

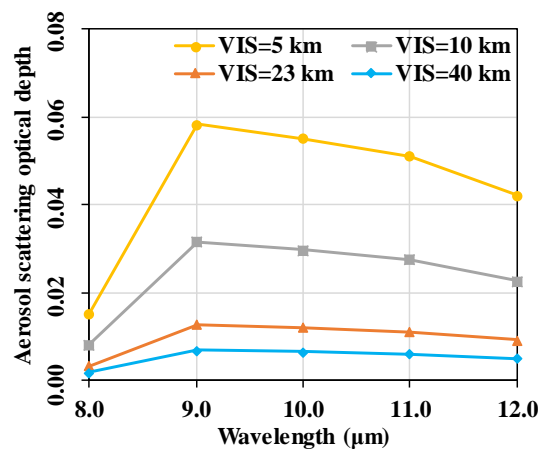

Fig. 18. Aerosol scattering optical depth (sum of the lower $3 \mathrm{~km}$ ) as a function of wavelength for different atmospheric visibilities (VIS). Wavelength and aerosol type were set as $10 \mu \mathrm{m}$ and RURAL, respectively.

Since aerosol scattering optical depth decreases with an increase in wavelength from $9.0 \mu \mathrm{m}$ to $12.0 \mu \mathrm{m}$, the adjacency effect should decrease with wavelength if atmospheric transmittances were the same at these wavelengths. However, when considering atmospheric transmittances at wavelengths of

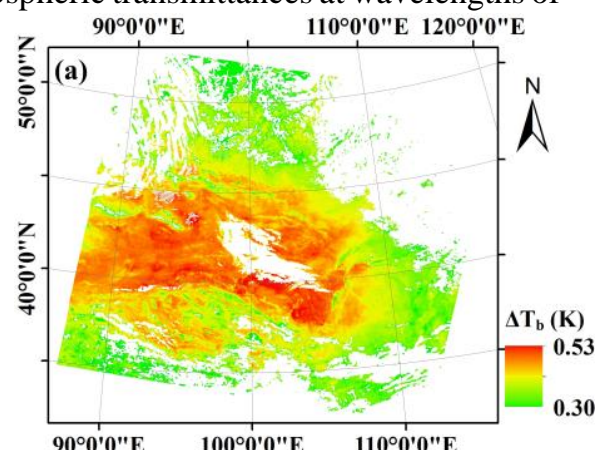

9.0, 10.0, 11.0, and $12.0 \mu \mathrm{m}$, the former three have similar values, but there is larger atmospheric transmittance at $12.0 \mu \mathrm{m}$. The decrease in the adjacency effect caused by decreasing aerosol scattering optical depth is therefore compensated for by the increase in atmospheric transmittance at $12.0 \mu \mathrm{m}$; this is expected to explain the small anomaly observed at $12.0 \mu \mathrm{m}$.

\section{G. Adjacency Effect Analysis on Actual Satellite Data}

In addition to the above point-based simulations, experiments using actual satellite data were also conducted, to preliminarily interpret adjacency effect magnitude in actual satellite measurements. MOD11, AST05, and AST08 products were used to provide the land surface radiation field. According to location and acquisition time of the selected study area images (see Section III.C), atmospheric transmittance, downwelling, and upwelling radiance were calculated by using the Mid-Latitude Winter atmospheric type provided in MODTRAN. The RURAL aerosol type and atmospheric visibility of $10 \mathrm{~km}$ were used to compute single scattered and target-reflected adjacent pixel radiance. Since FAERTM is a monochromatic model, the adjacency effect was first calculated wavelength by wavelength, then weighted using the MODIS and ASTER channel spectral response function (SRF). The results for Band 31 of MODIS and Band 14 of ASTER are given as examples. As shown in Fig. 19, the adjacency effect, defined according to (19), was present in every pixel for both images. For MODIS data with pixel size of $1000 \mathrm{~m} * 1000 \mathrm{~m}$ (Fig 19(a)), the maximum influence caused by the adjacency effect was about $0.5 \mathrm{~K}$. For ASTER data with pixel size of $90 \mathrm{~m} * 90 \mathrm{~m}$ (Fig 19(b)), even the minimum influence of the adjacency effect was $>1.0 \mathrm{~K}$.

We also considered the adjacency effect, using its definition as observed target radiation difference between a case with target-to-background-radiation-contrast and one without (21). As shown in Fig. 20, under this definition, there was very limited influence of the adjacency effect on satellite measurements for MODIS imagery. In the case of the ASTER image, which has much higher spatial resolution, the adjacency effect for pixels at radiation edges (such as river or lake shores) was as high as $0.35 \mathrm{~K}$. It can be assumed that in cases with higher spatial resolution measurements and larger targetbackground-contrast, the adjacency effect could be a little bit higher.

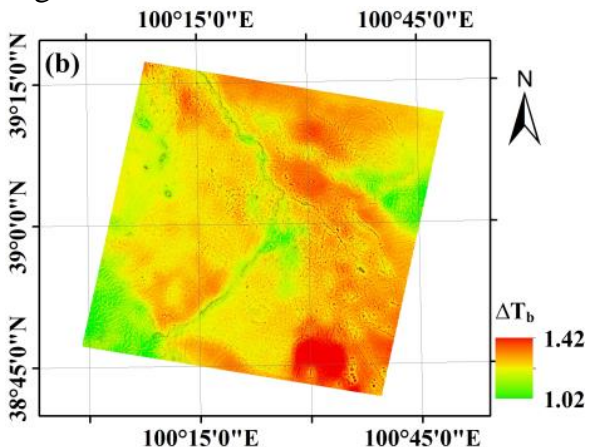

Fig. 19. Adjacency effect [defined as per (19)] results based on (a) MOD11 product (Band 31 with bandwidth of $10.78 \sim 11.28 \mu \mathrm{m}$ ), and (b) AST05 and AST08 products (Band 14 with bandwidth of $10.95 \sim 11.65 \mu \mathrm{m}$ ). Atmospheric type, atmospheric visibility and aerosol type were Mid-Latitude Winter, $10 \mathrm{~km}$, and RURAL, respectively. 


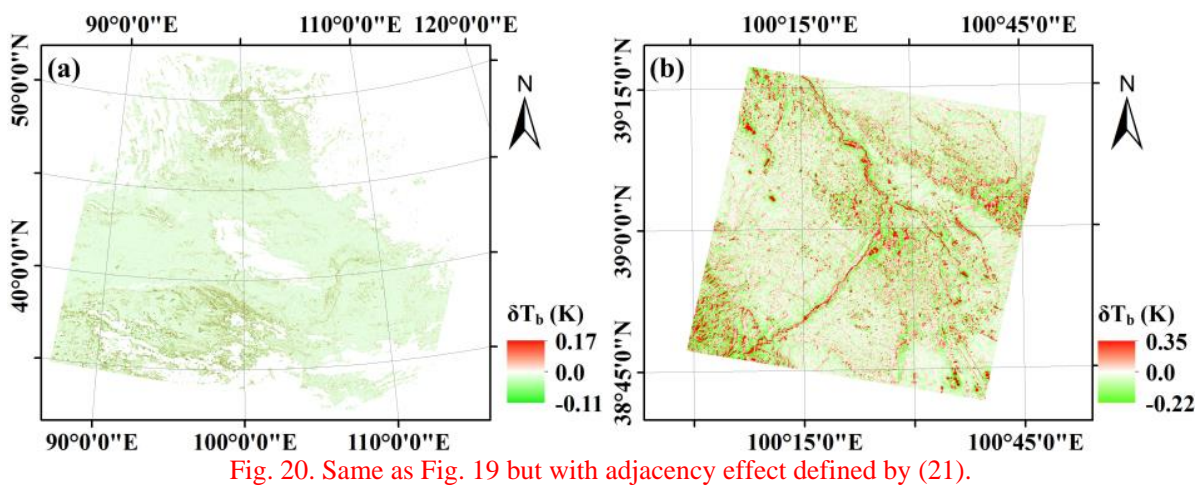

\section{DISCUSSIONS AND CONCLUSIONS}

Prior works have documented the development of a number of LST retrieval algorithms over the last several decades, such as the split window method, which has been successfully used to generate global LST products [13, 16, 64]. Existing LST retrieval algorithms assume a negligible adjacency effect or consider this to be already well addressed by TIR signals. To our knowledge, no studies have focused on quantifying the adjacency effect on TIR observations. As the TIR image spatial resolution improves nowadays, the adjacency effect on TIR satellite measurements needs to be studied to further improve LST retrieval accuracy. In this study, a physical adjacency effect simulation model, FAERTM, was developed. After comparison with MODTRAN, FAERTM was used to quantify the adjacency effect on TIR observations for different atmospheric and imaging conditions.

We found that the adjacency effect mainly originates from pixels within $3 \mathrm{~km}$ of the target and is not sensitive to aerosol type and LSE. Additionally, in contrast to scenarios with clear atmospheres, coarse image spatial resolution, and cold adjacent pixels, adjacency effect magnitude increased with a decrease in atmospheric visibility, an improvement in image spatial resolution, or an increase in adjacent pixel radiation. In extreme conditions, the adjacency effect magnitude may even exceed $3.0 \mathrm{~K}$. We also found that, as wavelength increased, the adjacency effect generally decreases, except at $8 \mu \mathrm{m}$; at this wavelength, atmospheric transmittance and aerosol scattering optical depth are both quite small, leading to most adjacency effect radiance being absorbed and thus not being observed by the sensor. This phenomenon has been confirmed using simulated path scattered radiance values from MODTRAN; the $8 \mu \mathrm{m}$ wavelength always has lower values than other wavelengths. For example, in a moderate humidity $\left(3.62 \mathrm{~g} / \mathrm{cm}^{2}\right)$ and turbid $(10 \mathrm{~km})$ atmosphere, path-scattered radiance at $8 \mu \mathrm{m}$ is about $4.63 \times 10^{-9}\left(\mathrm{~W} \mathrm{Sr}^{-1} \mathrm{~cm}^{-2} \mathrm{~cm}^{-1}\right)$, compared with $2.28 \times$ $10^{-8}\left(\mathrm{~W} \mathrm{Sr}^{-1} \mathrm{~cm}^{-2} \mathrm{~cm}^{-1}\right)$ at $9 \mu \mathrm{m}$.

These findings clearly show that the adjacency effect should be considered in the TIR region, at least for some specific cases, such as the atmospheric visibility is smaller than $23 \mathrm{~km}$ or the image spatial resolution is higher than $1.0 \mathrm{~km}$. Otherwise, significant underestimations would be introduced to the satellite observations. For the purpose of further improving LST retrieval accuracy, the adjacency effect should either be independently addressed from TIR signals before applying commonly used LST retrieval algorithms or should be integrated into existing LST retrieval algorithms to develop new ones. For each of the two potential approaches, the proposed FAERTM could be a useful tool because it can be used to quantitatively calculate this effect for given atmospheric and land surface conditions.

Although FAERTM can quantify the adjacency effect in different circumstances, some limitations are worth noting. All results obtained in this study are based on flat land surfaces and vertical observation assumptions. For rugged land surfaces, some of the energy coming from adjacent pixels would be directly reflected by the target pixel. Target-reflected adjacent pixel radiance should therefore increase; this requires further investigation. Moreover, the error in LST retrievals caused by the adjacency effect has not yet been discussed. Future work will focus on adding the three-dimensional structure of real land surfaces into FAERTM and evaluate the impact of the adjacency effect on LST retrieval results.

\section{ACKNOWLEDGMENT}

We would like to thank Dr. Xiaoyue GONG for her assistance in deducing the geometric relationships between adjacent pixel, scattering point, and remote sensor. We would also like to thank Prof. Changsen ZHAO for his advice on the organization of the manuscript. Special thanks are due to the anonymous reviewers for their valuable comments, which have been very helpful in improving manuscript quality.

\section{REFERENCES}

[1] M. C. Anderson, J. M. Norman, W. P. Kustas, R. Houborg, P. J. Starks, and N. Agam, "A thermal-based remote sensing technique for routine mapping of land-surface carbon, water and energy fluxes from field to regional scales," Remote Sens. Environ., vol. 112, no. 12, pp. 4227-4241, Dec. 2008.

[2] R. Zhang, J. Tian, H. Su, X. Sun, S. Chen, and J. Xia, "Two improvements of an operational two-layer model for terrestrial surface heat flux retrieval," Sensors (Basel), vol. 8, no. 10, pp. 6165-6187, Oct. 2008.

[3] W. Kustas and M. Anderson, "Advances in thermal infrared remote sensing for land surface modeling," Agric. For. Meteorol., vol. 149, no. 12, pp. 2071-2081, Dec. 2009.

[4] A. Karnieli, N. Agam, R. T. Pinker, M. Anderson, M. L. Imhoff, G. G. Gutman, N. Panov, and A. Goldberg, "Use of NDVI and land surface temperature for drought assessment: Merits and limitations," J Climate, vol. 23, no. 3, pp. 618-633, Feb. 2010.

[5] Z.-L. Li, B.-H. Tang, H. Wu, H. Ren, G. Yan, Z. Wan, I. F. Trigo, and J. A. Sobrino, "Satellite-derived land surface temperature: Current status and perspectives," Remote Sens. Environ., vol. 131, pp. 14-37, Apr. 2013.

[6] Z.-L. Liu, H. Wu, B.-H. Tang, S. Qiu, and Z.-L. Li, "Atmospheric corrections of passive microwave data for estimating land surface temperature," Opt. Express, vol. 21, no. 13, pp. 15654-15663, Jul. 2013. 
[7] S.-B. Duan, Z.-L. Li, and P. Leng, "A framework for the retrieval of allweather land surface temperature at a high spatial resolution from polarorbiting thermal infrared and passive microwave data," Remote Sens. Environ., vol. 195, pp. 107-117, Jun. 2017.

[8] J. Wen, Z. B. Su, and Y. M. Ma, "Determination of land surface temperature and soil moisture from tropical rainfall measuring mission/microwave imager remote sensing data," J. Geophys. Res.Atmos., vol. 108, no. D2, pp. 1-10, Jan. 2003.

[9] F. Sattari and M. Hashim, "A breife review of land surface temperature retrieval methods from thermal satellite sensors," Middle East J. Sci. Res., vol. 22, no. 5, pp. 757-768, 2014.

[10] J. C. Jimenez-Munoz and J. A. Sobrino, "A generalized single-channel method for retrieving land surface temperature from remote sensing data," J. Geophys. Res.-Atmos., vol. 108, no. D22, pp. 1-9, Nov. 2003.

[11] Z. Qin, A. Karnieli, and P. Berliner, "A mono-window algorithm for retrieving land surface temperature from Landsat TM data and its application to the Israel-Egypt border region," Int. J. Remote Sens., vol. 22, no. 18, pp. 3719-3746, Dec. 2001

[12] C. Ottle and D. Vidalmadjar, "Estimation of land surface-temperature with NOAA9 data," Remote Sens. Environ., vol. 40, no. 1, pp. 27-41, Apr. 1992.

[13] F. Becker and Z.-L. Li, "Towards a local split window method over land surfaces," Int. J. Remote Sens., vol. 11, no. 3, pp. 369-393, Mar. 1990.

[14] C. Coll and V. Caselles, "A split-window algorithm for land surface temperature from advanced very high resolution radiometer data: Validation and algorithm comparison," J. Geophys. Res.-Atmos., vol. 102, no. D14, pp. 16697-16713, Jul. 1997.

[15] L. M. McMillin, "Estimation of sea surface temperatures from two infrared window measurements with different absorption," J. Geophys. Res., vol. 80, no. 36, pp. 5113-5117, Dec. 1975.

[16] Z. Wan and J. Dozier, "A generalized split-window algorithm for retrieving land-surface temperature from space," IEEE Trans. Geosci. Remote., vol. 34, no. 4, pp. 892-905, Jul. 1996.

[17] Z. H. Qin, G. Dall'Olmo, A. Karnieli, and P. Berliner, "Derivation of split window algorithm and its sensitivity analysis for retrieving land surface temperature from NOAA-advanced very high resolution radiometer data," J. Geophys. Res.-Atmos., vol. 106, no. D19, pp. 22655-22670, Oct. 2001.

[18] J. A. Sobrino, Z. L. Li, M. P. Stoll, and F. Becker, "Multi-channel and multi-angle algorithms for estimating sea and land surface temperature with ATSR data," Int. J. Remote Sens., vol. 17, no. 11, pp. 2089-2114, Jul. 1996.

[19] A. Gillespie, S. Rokugawa, T. Matsunaga, J. S. Cothern, S. Hook, and A. B. Kahle, "A temperature and emissivity separation algorithm for advanced spaceborne thermal emission and reflection radiometer (ASTER) images," IEEE Trans. Geosci. Remote., vol. 36, no. 4, pp. 1113-1126, Jul. 1998.

[20] A. Chedin, N. A. Scott, and A. Berroir, "A single-channel, doubleviewing angle method for sea-surface temperature determination from coincident meteosat and Tiros-N radiometric measurements," J. Appl. Meteorol., vol. 21, no. 4, pp. 613-618, Apr. 1982.

[21] Z. Wan and Z.-L. Li, "A physics-based algorithm for retrieving landsurface emissivity and temperature from EOS/MODIS data," IEEE Trans. Geosci. Remote., vol. 35, no. 4, pp. 980-996, Jul. 1997.

[22] K. Watson, "Two-temperature method for measuring emissivity," Remote Sens. Environ., vol. 42, no. 2, pp. 117-121, Nov. 1992.

[23] Z.-L. Li, H. Wu, N. Wang, S. Qiu, J. A. Sobrino, Z. Wan, B.-H. Tang, and G. Yan, "Land surface emissivity retrieval from satellite data," Int. J. Remote Sens., vol. 34, no. 9-10, pp. 3084-3127, May 2013.

[24] F. Becker, "The impact of spectral emissivity on the measurement of land surface-temperature from a satellite," Int. J. Remote Sens., vol. 8, no. 10, pp. 1509-1522, Oct. 1987

[25] F. Becker and Z. L. Li, "Surface temperature and emissivity at various scales: Definition, measurement and related problems," Remote Sens. Rev., vol. 12, no. 3-4, pp. 225-253, 1995

[26] Z.-L. Li and F. Becker, "Feasibility of land surface-temperature and emissivity determination from AVHRR data," Remote Sens. Environ., vol. 43, no. 1, pp. 67-85, Jan. 1993.

[27] D. Burazerovic, R. Heylen, B. Geens, S. Sterckx, and P. Scheunders, "Detecting the adjacency effect in hyperspectral imagery with spectral unmixing techniques," IEEE J-Stars., vol. 6, no. 3, pp. 1070-1078, Jun. 2013.

[28] R. Richter, M. Bachmann, W. Dorigo, and A. Muller, "Influence of the adjacency effect on ground reflectance measurements," IEEE Geosci. Remote S., vol. 3, no. 4, pp. 565-569, Oct. 2006.
[29] E. F. Vermote, D. Tanré, J. L. Deuze, M. Herman, and J.-J. Morcette, "Second simulation of the satellite signal in the solar spectrum, 6S: An overview," IEEE Trans. Geosci. Remote., vol. 35, no. 3, pp. 675-686, May 1997.

[30] L. C. Sanders, J. R. Schott, and R. Raqueno, "A VNIR/SWIR atmospheric correction algorithm for hyperspectral imagery with adjacency effect," Remote Sens. Environ., vol. 78, no. 3, pp. 252-263, Dec. 2001

[31] S.-B. Duan, Z.-L. Li, B.-H. Tang, H. Wu, R. Tang, and Y. Bi, "Atmospheric correction of high-spatial-resolution satellite images with adjacency effects: Application to EO-1 ALI data," Int. J. Remote Sens., vol. 36, no. 19-20, pp. 5061-5074, Oct. 2015.

[32] D. Tanre, M. Herman, and P. Deschamps, "Influence of the background contribution upon space measurements of ground reflectance," Appl. Opt., vol. 20, no. 20, pp. 3676-3684, Oct. 1981.

[33] H. Ouaidrari and E. F. Vermote, "Operational atmospheric correction of Landsat TM data," Remote Sens. Environ., vol. 70, no. 1, pp. 4-15, Oct. 1999.

[34] R. Richter, "Correction of satellite imagery over mountainous terrain," Appl. Opt., vol. 37, no. 18, pp. 4004-4015, Jun. 1998.

[35] D. Tanre, P. Y. Deschamps, P. Duhaut, and M. Herman, "Adjacency effect produced by the atmospheric scattering in thematic mapper data," J. Geophys. Res.-Atmos., vol. 92, no. D10, pp. 12000-12006, Oct. 1987.

[36] R. Richter, "A fast atmospheric correction algorithm applied to Landsat TM images," Int. J. Remote Sens., vol. 11, no. 1, pp. 159-166, Jan. 1990.

[37] K. Thome, F. Palluconi, T. Takashima, and K. Masuda, "Atmospheric correction of ASTER," IEEE Trans. Geosci. Remote., vol. 36, no. 4, pp. 1199-1211, Jul. 1998.

[38] A. A. Semenov, A. V. Moshkov, V. N. Pozhidayev, A. Barducci, P. Marcoionni, and I. Pippi, "Estimation of normalized atmospheric point spread function and restoration of remotely sensed images," IEEE Trans. Geosci. Remote., vol. 49, no. 7, pp. 2623-2634, Jul. 2011.

[39] P. N. Reinersman and K. L. Carder, "Monte Carlo simulation of the atmospheric point-spread function with an application to correction for the adjacency effect," Appl. Opt., vol. 34, no. 21, pp. 4453-4471, Jul. 1995.

[40] W. A. Pearce, "Monte Carlo study of the atmospheric spread function," Appl. Opt., vol. 25, no. 3, pp. 438-447, Feb. 1986.

[41] J. Otterman and R. S. Fraser, "Adjacency effects on imaging by surface reflection and atmospheric scattering: Cross radiance to zenith," Appl. Opt., vol. 18, no. 16, pp. 2852-2860, Aug. 1979.

[42] Y. J. Kaufman, "Atmospheric effect on spatial resolution of surface imagery: Errata," Appl. Opt., vol. 23, no. 22, pp. 4164-4172, Nov. 1984.

[43] G. Yang, Q. Liu, Q. Liu, W. Huang, and J. Wang, "Simulation of highresolution mid-infrared (3-5 $\mu \mathrm{m})$ images using an atmosphere radiative transfer analytic model," Int. J. Remote Sens., vol. 30, no. 22, pp. 60036022, Nov. 2009.

[44] T. F. Eck, B. N. Holben, J. S. Reid, O. Dubovik, A. Smirnov, N. T. O'Neill, I. Slutsker, and S. Kinne, "Wavelength dependence of the optical depth of biomass burning, urban, and desert dust aerosols," J. Geophys. Res.-Atmos., vol. 104, no. D24, pp. 31333-31349, Dec. 1999.

[45] D. G. Kaskaoutis and H. D. Kambezidis, "Investigation into the wavelength dependence of the aerosol optical depth in the Athens area," Q. J. Roy. Meteor. Soc., vol. 132, no. 620, pp. 2217-2234, Oct. 2006.

[46] A. Ångström, "On the atmospheric transmission of sun radiation and on dust in the air," Geogr. Ann. A., vol. 11, no. 2, pp. 156-166, 1929.

[47] Y. J. Kaufman, A. Gitelson, A. Karnieli, E. Ganor, R. S. Fraser, T. Nakajima, S. Mattoo, and B. N. Holben, "Size distribution and scattering phase function of aerosol-particles retrieved from sky brightness measurements," J. Geophys. Res.-Atmos., vol. 99, no. D5, pp. 1034110356, May 1994

[48] Y. J. Kaufman, "Solution of the equation of radiative-transfer for remotesensing over nonuniform surface reflectivity," J. Geophys. Res.-Oceans., vol. 87, no. C6, pp. 4137-4147, May 1982.

[49] W. Jarosz, "Efficient Monte Carlo methods for light transport in scattering media," Ph.D. dissertation, UC San Diego, California, United States, 2008

[50] F. X. Kneisys, D. C. Robertson, L. W. Abreu, P. Acharya, G. P. Anderson, L. S. Rothman, J. H. Chetwynd, J. E. A. Selby, E. P. Shettle, W. O. Gallery, A. Berk, S. A. Clough, and L. S. Bernsterin, "The MODTRAN 2/3 report and LOWTRAN 7 model," G. D. Phillips Lab., Hanscom AFB, MA, USA, F19628-91-C-0132, Nov. 1996. [Online]. Available: http://web.gps.caltech.edu/ vijay/pdf/modrept.pdf, Accessed on: May 11, 2017. 
[51] D. Cimini, S. Frank, and G. Visconti, "Principles of radiometric remote sensing of the troposphere," in Integrated ground-based observing systems. 1st ed. Berlin, German: Springer-Verlag Berlin Heidelberg, 2010, ch. I.1, pp. 3-32.

[52] K.-N. Liou, "Light scattering by atmospheric particulates," in An introduction to atmospheric radiation. 2nd ed. San Diego, CA, USA: Academic press, 2002, ch. 5, pp. 169-257.

[53] F. X. Kneizys, E. Shettle, W. Gallery, J. Chetwynd Jr, and L. Abreu, "Atmospheric transmittance/radiance: Computer code LOWTRAN 6," A. F. G. H. A. L. (OPI), Hanscom AFB, MA, USA, AFGL-TR-83-0187, Aug. $1983 . \quad$ [Online]. Available: http://www.dtic.mil/dtic/tr/fulltext/u2/a137786.pdf, Accessed on: Jul. 7, 2017.

[54] Z. Wan, S. Hook, and G. Hulley, Mod11_12 MODIS/terra land surface temperature/emissivity 5-min 12 swath $1 \mathrm{~km}$ v006, U.S.A, N. E. L. DAAC, 2015. [Online]. Available: https://search.earthdata.nasa.gov, Accessed on: Feb. 5, 2019.

[55] A. M. A. J. Spacesystems and U. S. J. A. S. Team, ASTER level 2 surface temperature product, U.S.A, N. E. L. P. DAAC, 2001. [Online]. Available: https://search.earthdata.nasa.gov, Accessed on: Feb. 5, 2019.

[56] N. M. A. J. Spacesystems and U. S. J. A. S. Team, ASTER level 2 emissivity product, U.S.A, N. E. L. P. DAAC, 2001. [Online]. Available: https://search.earthdata.nasa.gov, Accessed on: Feb. 5, 2019.

[57] A. Berk, G. Anderson, P. Acharya, and E. Shettle, "MODTRAN 5 user's manual," A. F. R. L. S. V. Directorate, Hanscom AFB, MA, USA, Jul. $2008 . \quad$ [Online]. Available: ftp://ftp.pmodwrc.ch/stealth/132250_claus/MODTRAN5/Manual/MOD TRAN(R)5.2.0.0.pdf, Accessed on: Jun. 12, 2017.

[58] S. A. Clough, M. J. Iacono, and J. L. Moncet, "Line-by-line calculations of atmospheric fluxes and cooling rates - application to water-vapor," $J$. Geophys. Res.-Atmos., vol. 97, no. D14, pp. 15761-15785, Oct. 1992.

[59] R. G. Isaacs, W. C. Wang, R. D. Worsham, and S. Goldenberg, "Multiple scattering LOWTRAN and FASCODE models," Appl. Opt., vol. 26, no. 7, pp. 1272-1281, Apr. 1987.

[60] W.-C. Wang and P. B. Ryan, "Overlapping effect of atmospheric H2O, $\mathrm{CO} 2$ and $\mathrm{O} 3$ on the $\mathrm{CO} 2$ radiative effect," Tellus. B., vol. 35, no. 2, pp. 81-91, Aug. 1983.

[61] W. J. Wiscombe and G. W. Grams, "The backscattered fraction in twostream approximations," J. ATMOS. SCI., vol. 33, no. 12, pp. 2440-2451, Aug. 1976.

[62] J. Qiu, X. Zong, and X. Zhang, "A study of the scaling height of the tropospheric aerosol and its extinction coefficient profile," J. Aerosol Sci., vol. 36, no. 3, pp. 361-371, Mar. 2005.

[63] R. A. Reck, "Thermal and radiative effects of atmospheric aerosols in the northern hemisphere calculated using a radiative-convective model," Atmos. Environ., vol. 10, no. 8, pp. 611-617, Feb. 1976.

[64] Z. Wan, "New refinements and validation of the collection-6 MODIS land-surface temperature/emissivity product," Remote Sens. Environ., vol. 140, pp. 36-45, Jan. 2014.

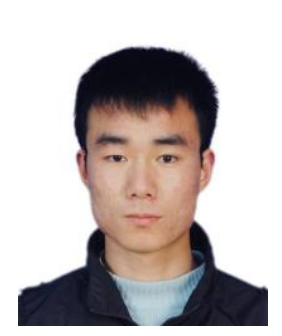

Xiaopo Zheng was born in Nanyang, Henan, China in 1991. He received the B.S. degree in remote sensing science and technology in 2013 from China University of Geosciences (Wuhan), China, the M.S. degree in cartography and geographical information system in 2016 from Peking University, China.

$\mathrm{He}$ is currently working toward the Ph.D degree at University of Strasbourg, Illkirch, France. satellites (EAGLE), and ESA-funded programs SPECTRA, etc. His main expertise fields are in thermal infrared radiometry, parameterization of land surface processes at large scale, and assimilation of satellite data to land surface models. He has published more than 100 papers in international refereed journals.

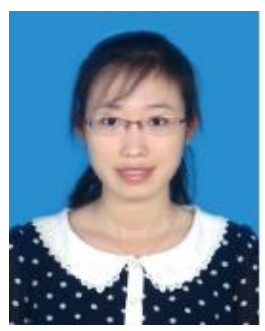

Xia Zhang was born in Shijiazhuang, Hebei, China in 1985. She received the B.S. degree in geographic information system in 2008 from Changchun Normal University, China, the M.S. and Ph.D. degrees in cartography and geographic information system in 2010 and 2014, both from the Northeast Normal University, China.

Since 2014, She has been a lecturer in the College of Land Resources and Urban and Rural Planning, Hebei GEO University, Shijiazhuang, China. Her research interest includes the thermal infrared polarization remote sensing, multi-angle and hyperspectral remote sensing and quantitative remote sensing.

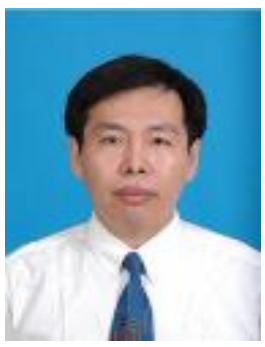

Guofei Shang was born in Tangshan,Hebei,China in 1964. He received the B.E. degree in aerial photogrammetry and remote sensing from the Wuhan University, Wuhan, Hubei, in 1985 and the M.E. and $\mathrm{Ph} . \mathrm{D}$. degrees in land resources management from Renmin University of China, Beijing, in 1992 and 2002.

Since 1997, he has been a professor and dean of College of Land Resources and Urban and Rural Planning, Hebei GEO University, China. His research interest includes the aerial photogrammetry and remote sensing, quantitative remote sensing and natural resources management.
Zhao-Liang Li received the B.A. degree in photogrammetry in 1985 from Wuhan Technical University of Surveying and Mapping, China, the M.S. degree in imaging processing and computer graphics in 1987, and his Ph.D. degree in terrestrial environmental physics in 1990, both from the University of Louis Pasteur, Strasbourg, France.

Since 1992, he has been a Research Scientist with CNRS, Illkirch, France. He joined the Institute of Agricultural Resources and Regional Planning in 2013. $\mathrm{He}$ has participated in many national and international projects such as the National Aeronautics and Space Administration (NASA)-funded Moderate Resolution Imaging Spectroradiometer, European Community (EC)-funded program Exploitation of angular effects in land surface observations from 